\title{
Melanoma and medical education: knowledge and sun safety practices amongst medical students
}

\author{
Nicolina Smith ${ }^{1}$, Margaret Finn², Larry Segars ${ }^{3}$, Erin Burns ${ }^{2}$, Johanna Peterson 4 , \\ Angela Sutton ${ }^{3}$, Kaitlin Vogt ${ }^{2}$, Molly Menser ${ }^{5}$
}

\begin{abstract}
${ }^{1}$ Department of Anatomy, Kansas City University of Medicine and Biosciences. Kansas City, Missouri, USA, ${ }^{2}$ Department of Dermatology, The University of Missouri. Kansas City, Missouri, USA, ${ }^{3}$ Department of Pharmacology, Kansas City University of Medicine and Biosciences. Kansas City, Missouri, USA, ${ }^{4}$ Department of Dermatology, The University of Kansas Hospital. Kansas City, Missouri, USA, ${ }^{5}$ Dermatology, Sunflower Dermatology and Medical Day Spa. Kansas City, Missouri, USA
\end{abstract}

Corresponding author: Dr. Nicolina Smith., E-mail: NMSmith@Kcumb.edu

\begin{abstract}
Introduction: Melanoma has become a public health problem; however, with proper education and the use of sun safety techniques, most cases can be prevented. The purpose of this study is to determine if medical students have safer sun practices than the general population. Material and Methods: An online survey was sent to all students enrolled in the three medical schools in the Kansas City metropolitan area. Surveys were sent to 1200 medical students with a 39.25\% response rate $(n=471)$. Results: Most of the student population $(n=436 ; 92.6 \%)$ indicated that over the past year they had used one or more forms of sun protection. Of the respondents, $60.7 \%(\mathrm{n}=286)$ indicated they had, to this point in their medical training, been educated counseling patients about the risk factors for prevention of skin cancer. Respondents who indicated that they had been educated on the steps/procedures of a complete skin exam were significantly more likely to indicate they had used sun protective equipment in the past year $(\mathrm{P}=.024)$. Conclusions: The general population is in need of dermatologic education on the basic risk factors of skin cancer as well as ways to prevent skin cancer. As education increases in the general population one would anticipate that these individuals would engage in safe sun practices as seen in the medical student community.
\end{abstract}

Key words: Dermatology curriculum; Melanoma; Sun safety; Preventative medicine

\section{INTRODUCTION}

Skin cancer is the most prevalent type of cancer in the United States [1]. Of the three major types of skin cancer, melanoma is the least prevalent; however, it is responsible for $75 \%$ of skin cancer deaths [2] Every 52 minutes one person dies of melanoma in the United States. This is alarming when considering for over 40 years the incidence of melanoma in the United States has been increasing. Melanoma has become a public health problem; however, with proper education and the use of sun safety techniques, most cases of this deadly disease are possibly preventable [3].

Patients with nonmelanoma and melanoma skin cancers often initially present to a non-dermatologist, suggesting that more physicians need to have the clinical skills to diagnose worrisome lesions and counsel on proper sun protective practices [4-6]. Physicians with better personal health practices are more likely to have better attitudes towards counseling patients, counsel a broader range of patients and counsel more frequently [7]. We investigated the level of education and personal practices of medical students regarding skin examinations and sun protection habits.

\section{MATERIAL AND METHODS}

A detailed medical literature review was initially performed looking at the habits and experiences of the general public in relation to sun exposure and indoor

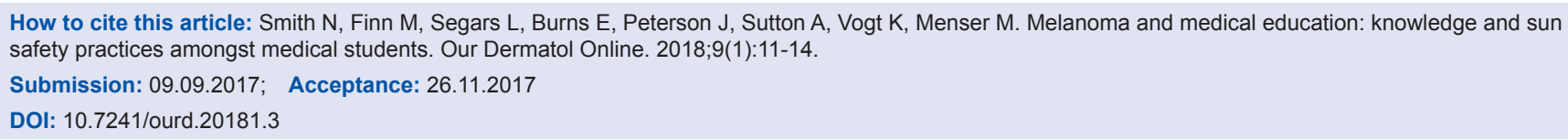


tanning bed use, as well as the research available on medical student training with safe skin practices and skin examination. From this literature evaluation we developed a survey that had two primary sections and included a total of 22 questions. These questions assessed the skin characteristics of each student as well as their personal sun practices.

The survey was distributed via school-specific email accounts in the fall semester of 2012 to all medical students, MS1 to MS4, $(n=1200)$ from the following medical schools: University of Kansas School of Medicine, University of Missouri-Kansas City School of Medicine, and Kansas City University of Medicine and Biosciences. Study data was collected and managed using the Research Electronic Data Capture (REDCap) (Vanderbilt University, Copyright 2016) electronic data capture tool hosted at the University of MissouriKansas City. REDCap is a secure, web-based application designed to support data capture for research studies. The respective Institutional Review Boards at each of the participating medical schools approved this study.

Survey responses were reviewed for completeness. Surveys submitted without responses were removed and not included in the final study population or descriptive statistics $(n=2)$. Descriptive statistics were generated for all survey items and an initial univariate analysis was performed on each item through use of the chi-square test. Correlations were also performed to evaluate direction and magnitude of any significant associations found between survey items. Sequential and systematic stratified univariate and multivariate logistic and multinomial regression analyses, as appropriate, were conducted to assess for significance, confounding and effect modification on selected items utilized as outcome variables. All variables found to be statistically significant or to be associated with confounding/ interaction were utilized in the final regression models. Odds ratios (OR) and 95\% confidence intervals (CI) were determined from regression modeling and all tests for significance were two-tailed with an a priori level of $0.05(P=.05)$. Stata statistical software package (SE version 9.2; Stata Corp., College Station, Texas) was utilized for all analyses.

\section{RESULTS}

An estimated total of 1200 medical students were surveyed and resulted with a $39.25 \%$ response rate $(n=471)$. Most of the student population $(n=436$; 92.6\%) indicated that over the past year they had used one or more forms of sun protection. Only 10.4\% $(n=49)$ of the respondents indicated they had used a tanning bed during the past year (Table 1).

Of the respondents, $60.7 \%(n=286)$ indicated they had, to this point in their medical training, been educated on counseling patients about the risk factors for prevention of skin cancer. Medical student respondents who indicated they had been educated on how to perform a complete skin examination were significantly more likely to use protective sun equipment in the past year $(P=.024)$. Respondents who indicated they had been educated on the performance of a complete skin examination indicated they were significantly more likely to seek shade while outside $(P=.003)$, avoid peak sun hours $(P=.030)$, use creams, sprays, or other artificial tanning products to have tan skin $(P=.011)$. Students who had been educated on the performance of a complete skin examination also indicated that medical education changed their personal belief in tanned skin $(P=.005)$. They felt it was very important to counsel patients on the risk factors and prevention of skin cancer $(P=.040)$ and, they had a higher total number of sun protection practices $(P=.003)$ (Table 2$)$.

Medical student respondents who indicated they had been educated on how to counsel patients on the risk factors and prevention of skin cancer were significantly more likely to indicate they seek shade as much as possible $(P=.049)$, avoid peak sun hours $(P=.010)$, believe that their medical education had changed their beliefs about tanned skin, and would be more likely to perform a complete skin exam on their future patients $(P=.001)$. These students were also less likely to use a tanning booth in the past year $(P=.003)$ (Table 3).

\begin{tabular}{lc} 
Table 1: Medical student sun practices & \\
\hline Utilized forms of sun protection in past year & \\
Yes & $436(92.6)$ \\
No & $32(6.8)$ \\
No response & $3(0.6)$ \\
Spent time in sun to tan in past year & \\
Yes & $266(56.5)$ \\
No & $203(43.1)$ \\
No response & $2(0.4)$ \\
Utilized a tanning bed/booth in past year & \\
Yes & $49(10.4)$ \\
No & $418(88.7)$ \\
No response & $4(0.8)$ \\
\hline
\end{tabular}

$\$$ Includes sunscreen, protective clothing/equipment (e.g., long sleeves, long pants, hat, umbrella), seeking shade as much as possible (e.g., trees, buildings, awnings), or avoiding peak sun hours (e.g., 10 a.m. to 4 p.m.) 
Table 2: Comparing medical students who were educated about risk factors and prevention of skin cancer and the use of sun protection practices

\begin{tabular}{|c|c|}
\hline \multicolumn{2}{|c|}{$\begin{array}{l}\text { Educated on counseling patients about risk factors for/ } \\
\text { prevention of skin cancer }\end{array}$} \\
\hline Yes & $286(60.7)$ \\
\hline No & $185(39.3)$ \\
\hline No response & $0(0.0)$ \\
\hline \multicolumn{2}{|c|}{$\begin{array}{l}\text { Educated on steps/procedures in performing complete skin } \\
\text { examination }\end{array}$} \\
\hline Yes & $139(29.5)$ \\
\hline No & $331(70.3)$ \\
\hline No response & $1(0.2)$ \\
\hline \multicolumn{2}{|l|}{ Total sun protection practices $f$} \\
\hline 0 & $36(7.6)$ \\
\hline 1 & $153(32.5)$ \\
\hline 2 & $124(26.3)$ \\
\hline 3 & $104(22.1)$ \\
\hline 4 & $54(11.5)$ \\
\hline No response & $0(0.0)$ \\
\hline \multicolumn{2}{|l|}{ Utilized artificial tanning products $¥$} \\
\hline Yes & $92(19.5)$ \\
\hline No & $376(79.8)$ \\
\hline No response & $3(0.6)$ \\
\hline \multicolumn{2}{|c|}{ Believe medical education has changed desire for tanned skin } \\
\hline Yes & $171(36.3)$ \\
\hline No & $186(39.5)$ \\
\hline Not applicable & $112(23.8)$ \\
\hline No response & $2(0.4)$ \\
\hline \multicolumn{2}{|c|}{$\begin{array}{l}\text { How likely to perform annual complete skin examination on } \\
\text { future patients }\end{array}$} \\
\hline Very likely & $109(23.1)$ \\
\hline Somewhat likely & $210(44.6)$ \\
\hline Neither likely or unlikely & 78 (16.6) \\
\hline Somewhat unlikely & $40(8.5)$ \\
\hline Very unlikely & $34(7.2)$ \\
\hline No response & $0(0.0)$ \\
\hline \multicolumn{2}{|c|}{$\begin{array}{l}\text { Importance of counseling patients about risk factors for/ } \\
\text { prevention of skin cancer }\end{array}$} \\
\hline Very important & $299(63.5)$ \\
\hline Somewhat important & $165(35.0)$ \\
\hline Neither important or unimportant & $4(0.8)$ \\
\hline Somewhat unimportant & $0(0.0)$ \\
\hline Very unimportant & $0(0.0)$ \\
\hline No response & $3(0.6)$ \\
\hline
\end{tabular}

$f$ Total sum of individually designated sun protection practices (e.g., use of sunscreen; use of protective clothing/equipment (e.g., long sleeves, long pants, hat, umbrella); seeking shade as much as possible e.g., trees, buildings, awnings); avoiding peak sun hours (e.g., 10 a.m. to 4 p.m.)

*Includes spray tans, tanning creams or tinted moisturizers.

\section{DISCUSSION}

Adult medical students (92.6\%) are more likely to use one or more forms of sun protection in comparison to the general U.S. adult (18 and older) population $(70 \%)$ [1]. The correlations performed in our study suggest that medical students who have been educated on the steps and procedures of a complete skin examination were more likely to use forms of protective sun equipment and believed their medical education
Table 3: Comparing medical students who were educated versus those who were not on the behaviors above

\begin{tabular}{lc}
\hline Educated on counseling patients about risk factors for \\
prevention of skin cancer \\
Yes \\
No & $286(60.7)$ \\
No response & $185(39.3)$ \\
Total sun protection practices & $0(0.0)$ \\
0 & \\
1 & $36(7.6)$ \\
2 & $153(32.5)$ \\
3 & $124(26.3)$ \\
4 & $104(22.1)$ \\
No response & $54(11.5)$ \\
Believe medical education has changed desire for tanned skin & $0(0.0)$ \\
Yes & \\
No & $171(36.3)$ \\
Not applicable & $186(39.5)$ \\
No response & $112(23.8)$ \\
Utilized a tanning bed/booth in past year & $2(0.4)$ \\
Yes & \\
No & $49(10.4)$ \\
No response & $418(88.7)$ \\
\hline
\end{tabular}

had changed their belief of tan skin. Medical students who indicated they had been educated on how to counsel patients about risk factors and prevention were also more likely to seek shade when possible, avoid peak sun hours, and believe that their medical education has changed their beliefs about tanned skin. Our analyses suggest that medical school students have better sun protective practices because they are educated about skin cancer and potential risk factors. Thus, there could be a positive correlation between the amount an individual is educated about risk factors and prevention of skin cancer and the likelihood of engaging in safe skin practices. These findings should encourage primary care physicians as well as dermatologists to reach out to communities and offer education to the general public about skin cancer.

The lack of education amongst the adult population translates to the lack of parent sun-protection practices for children. Framingham, Massachusetts conducted a population-based study showing that $55 \%$ of children reported experiencing one or more sunburns during the prior summer and, more alarmingly, only $25 \%$ routinely used sunscreen [8]. There is a need to integrate sunscreen use into children's daily routines to reduce their risk of developing skin cancer.

With the rates of skin cancer increasing it is also important to consider the economical impact. The annual cost of melanoma treatment has increased by 288\% from 2002 to 2006 and from 2007 to 2011.6 This 
is high, especially when you compare it to treatment for all other cancers, which has only increased by $25 \%$ within the same timeframe. In the United States, skin cancer treatment costs $\$ 8.1$ billion and of that $\$ 3.3$ billion is from melanoma [9-13].

The level of skin cancer education in the general public is a problem that needs to be addressed. The Community Guide, which was made by The Community Preventive Services Task Force, states that there is enough evidence to recommend education approaches to increase the knowledge of preventative behaviors amongst child care centers, schools, and occupational settings. The Community Guide states that multicomponent interventions are the most effective when implementing preventative behaviors. The interventions must have two distinct components which can be any combination of the following: individual strategy, mass media campaign, or environmental and policy changes. ${ }^{[14,15]}$ Using these guidelines to create a skin cancer campaign, education of the general population should increase and, in turn, raise their likelihood to engage in adequate sun safety techniques.

\section{CONCLUSIONS}

Our study compared medical students who are educated on safe sun practices and risk factors of skin cancer to students who are not yet educated on these topics. These results led us to believe that education makes a difference in a person's likelihood to engage in safe sun practices. This could be the reason for such a gap in sun safety practices between the medical students we studied and the general population. In order to educate individuals of all socioeconomic statuses, the knowledge could potentially be transmitted as a public service campaign. As the general population becomes more aware about skin cancer risk factors and sun safety practices, the prevalence of this form of cancer should decrease.

\section{REFERENCES}

1. Centers for Disease Control and Prevention, National Center for Health Statistics. UV Exposure and Sun Protective Practices. National Health Interview Survey NCI and CDC Co-sponsored
Cancer Control Supplement, 1992-2010, 2005-2010. progressreport. cancer.gov/sun_protection. Accessed June 15, 2016.

2. US Cancer Statistics Working Group. United States Cancer Statistics: 1999-2012 Incidence and Mortality. Web-based report. Atlanta, GA: Centers for Disease Control and Prevention; 2015. cdc.gov/uscs. Accessed June 9, 2016.

3. US Department of Health and Human Services. The Surgeon General's Call to Action to Prevent Skin Cancer. Washington, DC: US Department of Health and Human Services, Office of the Surgeon General; 2014. surgeongeneral.gov/library/calls/preventskin-cancer/call-to-action-prevent-skin-cancer.pdf. Accessed June 12, 2016.

4. Lin JS, Eder M, Weinmann S. Behavioral counseling to prevent skin cancer: a systematic review for the U.S. Preventive Services Task Force. Ann Intern Med. 2011;154:190-201.

5. Moyer VA, U.S. Preventive Services Task Force. Behavioral counseling to prevent skin cancer: U.S. Preventive Services Task Force recommendation statement. Ann Intern Med. 2012;157:59-65.

6. U.S. Preventive Services Task Force. Behavioral counseling to prevent skin cancer: U.S. Preventive Services Task Force recommendation statement website. http:/ / www.uspreventiveservicestaskforce.org/ uspstf11/skincancouns/skincancounsrs.htm. Accessed May 16, 2013.

7. Wells KB, Lewis CE, Leake B, Ware JE Jr. Do physicians preach what they practice? a study of physician's health habits and counseling practices. JAMA 1984;2522846-2848.

8. Dusza SW, Halpern AC, Statagopan JM, Oliveria SA, Weinstock MA, Scope A, et al. Prospective study of sunburn and sun behavior patterns during adolescence. Pediatrics. 2012;129:309-17.

9. Guy GP Jr, Machlin SR, Ekwueme DU, Yabroff KR. Prevalence and costs of skin cancer treatment in the US, 2002-2006 and 20072010. Am J Prev Med. 2015;48;183-7.

10. Jemal A, Saraiya M, Patel P, Cherala SS, Barnholtz-Sloan J, Kim J, et al. Recent trends in cutaneous melanoma incidence and death rates in the United States, 1992-2006. J Am Acad Dermatol. 2011;65(5 suppl 1):S17.e01-S17.e11.

11. Lomas A, Leonardi-Bee J, Bath-Hextall F. A systematic review of worldwide incidence of nonmelanoma skin cancer. Br J Dermatol. 2012;166:1069-80.

12. Machlin S, Carper K, Kashihara D. Health care expenditures for non-melanoma skin cancer among adults, 2005-2008 (average annual). Statistical Brief \#345. Rockville, MD: Agency for Healthcare Research and Quality; 2011. http://www.meps.ahrq. gov/mepsweb/data_files/publications/st345/stat345.shtml. Accessed January 16, 2014.

13. Stern RS. Prevalence of a history of skin cancer in 2007: results of an incidence-based model. Arch Dermatol. 2010;146:279-82.

14. Balk SJ, Council on Environmental Health, Section on Dermatology. Ultraviolet radiation: a hazard to children and adolescents. Pediatrics. 2011;127:e791-e817.

15. Community Preventive Services Task Force. Preventing Skin Cancer: Education and Policy Approaches. thecommunityguide. org/cancer/skin/education-policy/index.html. Accessed June 2, 2016.

Copyright by Nicolina Smith, et al. This is an open access article distributed under the terms of the Creative Commons Attribution License, which permits unrestricted use, distribution, and reproduction in any medium, provided the original author and source are credited. Source of Support: Nil, Conflict of Interest: None declared. 